NASA Technical Memorandum 106391

AIAA-94-0582

\title{
Evaluation of Turbulence Models in the PARC Code for Transonic Diffuser Flows
}

N.J. Georgiadis

Lewis Research Center

Cleveland, Ohio

and

J.E. Drummond and B.P. Leonard

The University of Akron

Akron, Ohio

Prepared for the

32nd Aerospace Sciences Meeting and Exhibit

sponsored by the American Institute of Aeronautics and Astronautics

Reno, Nevada, January 10-13, 1994

\section{N/Sn}




\title{
EVALUATION OFTURBULENCE MODELS IN THE PARC CODE FOR TRANSONIC DIFFUSER FLOWS
}

\author{
N. J. Georgiadis* \\ NASA Lewis Research Center \\ Cleveland, Ohio 44135 \\ and
J.E. Drummond and B. P. Leonard
The University of Akron
Akron, Ohio 44325

\section{$\underline{\text { Abstract }}$}

Flows through a transonic diffuser were investigated with the PARC code using five turbulence models to determine the effects of turbulence model selection on flow prediction. Three of the turbulence models were algebraic models: Thomas (the standard algebraic turbulence model in PARC), Baldwin-Lomax, and Modified Mixing LengthThomas (MMLT). The other two models were the low Reynolds number $\mathrm{k}-\varepsilon$ models of Chien and Speziale. Three diffuser flows, referred to as the no-shock, weak-shock, and strong-shock cases, were calculated with each model to conduct the evaluation. Pressure distributions, velocity profiles, locations of shocks, and maximum Mach numbers in the duct were the flow quantities compared. Overall, the Chien $k-\varepsilon$ model was the most accurate of the five models when considering results obtained for all three cases. However, the MMLT model provided solutions as accurate as the Chien model for the no-shock and the weak-shock cases, at a substantially lower computational cost (measured in CPU time required to obtain converged solutions). The strong shock flow, which included a region of shockinduced flow separation, was only predicted well by the two $\mathrm{k}-\varepsilon$ models.

\section{Nomenclature}

$\mathrm{H} \quad$ diffuser height (varying through duct)

$\mathrm{H}_{\mathrm{T}} \quad$ diffuser height at throat

k turbulent kinetic energy

P static pressure

$\mathrm{P} \quad$ inflow total pressure (also reference pressure)

$\mathrm{P}_{\sigma} \quad$ standard deviation of pressure

$\mathrm{R}$ ratio of outflow static pressure to inflow total pressure, $\mathrm{P} / \mathrm{P}$ 。

$\mathrm{U}_{\text {ref }} \quad$ reference velocity (speed of sound based on reference temperature and pressure)

V velocity

$\mathrm{x}, \mathrm{y} \quad$ Cartesian coordinates

$\mathrm{y}^{+} \quad$ nondimensional vertical position

$\varepsilon \quad$ rate of turbulent kinetic energy dissipation $\underline{\text { Introduction }}$

Computational fluid dynamics (CFD) is now being used extensively to analyze flows through advanced propulsion systems. These flows often include characteristics such as attached and separated turbulent boundary layers, oblique and normal shocks, shock wave/boundary layer interactions, turbulent mixing, and other complex phenomena. The most sophisticated CFD codes employing Navier-Stokes solvers are required to analyze propulsion components with flow characteristics such as these. Despite the advances in flow solving capabilities, the ability of Navier-Stokes solvers to calculate complex flows is strongly dependent on the turbulence model employed.

In the current study, flows through a transonic diffuser were calculated with the PARC code, a general purpose Navier-Stokes solver for fluid flow simulation, using five of the turbulence models installed in PARC. Calculations obtained with PARC using each turbulence model were compared with experimental data to determine the effects of turbulence model selection on the prediction of diffuser flows. The flow quantities under comparison were the pressure distributions along the top and bottom walls of the diffuser, velocity profiles, locations of shocks in the flows, and Mach numbers in the duct. The computational cost required to obtain solutions using the different turbulence models was also considered.

The following sections describe the PARC code and turbulence models used in the study, diffuser cases that were examined, and comparison of PARC calculations with experimental data.

\section{The PARC Code}

The PARC code ${ }^{1.2}$ is an internal flow Navier-Stokes code used extensively by government and industry to analyze propulsion flows, especially those of aircraft engine inlets and nozzles. PARC was derived from the ARC

\footnotetext{
* Member AIAA
} 
external flow Navier-Stokes code. ${ }^{3.4}$ One version of the PARC code contains the two-dimensional and axisymmetric solver (PARC2D) whereas the other version contains the three-dimensional solver (PARC3D). The governing equations of motion are the time-dependent Reynolds averaged Navier-Stokes equations satisfying a perfect gas relationship and Fourier's heat conduction law. These equations are discretized in conservation law form with respect to general curvilinear coordinates and solved with the Beam and Warming approximate factorization algorithm. ${ }^{5}$ Although a time-dependent solver based on the work of Jameson ${ }^{6}$ is available, PARC is intended for steadystate flow simulations.

\section{Turbulence Models in PARC}

Three of the turbulence models investigated in this study are algebraic (zero-equation) models and two are energy-dissipation rate $(\mathrm{k}-\varepsilon)$ two-equation models. They will be described here briefly. The algebraic models are the Thomas, Baldwin-Lomax, and Modified Mixing LengthThomas (MMLT) models. The Thomas model (based on the work of Ref. 7) is the standard algebraic turbulence model in PARC. This model calculates turbulent viscosity near surfaces (wall-bounded part of the model) and in regions where flows are mixing (free-shear layer part of the model) but is optimized for the latter. The Baldwin-Lomax algebraic turbulence model ${ }^{8}$ is also available in PARC. This model only calculates turbulent viscosity in wall-bounded regions. The third algebraic model uses the Modified Mixing Length (MML) model (originally developed to analyze iced airfoils) $)^{9}$ for wall-bounded regions and the Thomas model for free-shear layer regions. This combination turbulence model was developed from its two components in Ref. 10 and is referred to as the MMLT model for the rest of this discussion.

Algebraic turbulence models such as those described here often model complex flows inadequately because they use single mixing length distributions to calculate turbulent viscosity, which often are not applicable to all flows. Twoequation models avoid this single mixing length limitation by using additional transport equations to calculate turbulent viscosity. However, these models are substantially more computationally expensive. The two-equation models that have been installed in PARC and were investigated in this study are the Chien low Reynolds number $k-\varepsilon$ mode ${ }^{11}$ with modifications for compressibility added by Nichols ${ }^{12}$ and the low Reynolds number $k-\varepsilon$ model based upon the work of Speziale. ${ }^{13}$

\section{Discussion of Flow Cases}

The transonic diffuser flows considered in this study are those described in Refs. 14-17. This two-dimensional diffuser with a convergent-divergent channel was designed to simulate the types of flows that exist in supersonic inlets of aircraft engines. Extensive flow measurements were made during tests of this diffuser for flows with and without externally applied oscillations. Only the experimental results for unexcited flows were examined for comparison with PARC flow calculations.

A schematic of the diffuser geometry is shown in Fig.1. The diffuser had an entrance-to-throat area ratio of 1.4 and an exit-to-throat area ratio of 1.5. The distance between sidewalls was approximately four throat heights. Suction slots were placed in the sidewalls and top corners to keep the flow two-dimensional. Three flows were investigated with PARC2D using the five turbulence models. These flows were defined by the ratio of the exit static pressure to the inflow total pressure $(\mathrm{R})$ and are referred to as the no-shock $(R=0.862)$, weak-shock $(R=0.82)$, and strong-shock $(R=0.72)$ cases. The inflow total temperature was approximately $300 \mathrm{~K}$ and the outflow static pressure was atmospheric for all cases.

\section{No-Shock Case}

The first flow examined with PARC was that with no shock forming in the duct. The back pressure $(R=0.862)$ was high enough to prevent supersonic flow from forming in the diffuser downstream of the throat. A grid sensitivity investigation was conducted using this no-shock case before PARC solutions using the five turbulence models were compared with each other and with experimental data. This grid sensitivity study is discussed next.

Similar numerical studies ${ }^{18-22}$ used a computational grid having 81 points in the horizontal direction and 51 points in the vertical direction $(81 \times 51)$. The two grids constructed for this investigation are shown in Fig. 2 . The first grid had $81 \times 51$ points with the point next to either wall placed in the laminar sublayer $\left(\mathrm{y}^{+}<5\right)$. The second grid also had 81 points in the horizontal direction but a total of 81 points in the vertical direction. These extra points in the second grid were used to pack the boundary layer regions more tightly with the point next to the wall at a distance corresponding to $\mathrm{y}^{+} \sim 1$. For each turbulence model, the solution obtained with the $81 \times 51$ grid was compared to the solution obtained with the $81 \times 81$ grid to determine grid sensitivity.

Only the Speziale k- $\varepsilon$ model results showed significant differences between solutions obtained with the two grids. Low Reynolds number k- $\varepsilon$ turbulence models often require more tightly packed grids than other turbulence models, such as the three algebraic models investigated in this study. Not only should the first grid point from the wall be placed in the laminar sublayer, it should correspond to a position of $y^{+} \sim 1$. Avva, Smith, and Singhal ${ }^{23}$ report that if the first grid point is placed in the logarithmic layer instead of the laminar sublayer when using low Reynolds number 
$k-\varepsilon$ turbulence models, the peak value of turbulent kinetic energy can increase by a factor of 2 , thus creating inaccurate flow predictions. Figure 3 shows a comparison of turbulent kinetic energy profiles obtained from the Chien and Speziale $k-\varepsilon$ solutions along the bottom wall of the diffuser at the throat. The Chien model produces similar profiles (see Fig. 3a) for solutions obtained with the two grids. The turbulent viscosity was much lower than the molecular viscosity at the first point off the wall for both grids. This indicates that the first points were in the laminar sublayer.

The Speziale model results (Fig. 3b) show that the turbulent kinetic energy in the near wall region calculated with the $81 \times 51$ grid is substantially higher than that calculated using the $81 \times 81$ grid. Also, the turbulent viscosity at the first point off the wall was higher than the molecular viscosity for the $81 \times 51$ grid, indicating that the first point was outside the laminar sublayer. The turbulent viscosity calculated with the $81 \times 81$ grid did not exceed the molecular viscosity until the third or fourth point away from the wall. Based upon this grid sensitivity investigation, the $81 \times 51$ grid is sufficient for the three algebraic turbulence models and the Chien k- $\varepsilon$ model, but the $81 \times 81$ grid is required for the Speziale k- $\varepsilon$ model to obtain calculations that compare with the experimental data. A comparison of PARC solutions with experimental data follows next.

Pressure distributions obtained from the PARC calculations are compared with experimental pressures along the top and bottom walls of the diffuser in Fig. 4. The Baldwin-Lomax and Thomas solutions predicted pressures near the throat $\left(\mathrm{x} / \mathrm{H}_{\mathrm{T}} \sim 0\right)$ that are too low compared with the experimental data whereas the Speziale k- $\varepsilon$ solutions predicted pressures that are too high. The Chien and MMLT solutions predicted pressures in this location more accurately than the other models. Mach number gray-scale contours for the no-shock flow (Chien $k-\varepsilon$ solution) are shown in Fig. 5 and the maximum Mach numbers in the diffuser using each turbulence model are listed in Table 1. These maximum Mach numbers (occurring at the throat) correspond to the pressure distributions of Fig. 4. That is, the Baldwin-Lomax and Thomas solutions have the highest maximum Mach numbers corresponding to their lowest pressures at the throat. Also, the Speziale solution produces the lowest maximum Mach number in the diffuser corresponding to its highest pressures at the throat.

Table 1.- Calculated flow properties for the no-shock flow.

\begin{tabular}{|l|c|}
\hline Case & $\begin{array}{c}\text { Maximum Mach } \\
\text { number in duct }\end{array}$ \\
\hline Thomas & 0.863 \\
Baldwin-Lomax & .872 \\
MMLT & .828 \\
Chien k- $\varepsilon$ & .813 \\
Speziale k- $\varepsilon$ & .779 \\
\hline
\end{tabular}

Convergence was determined when the residual error dropped several orders of magnitude and when the solutions did not change with more iterations. Convergence histories for all the solutions are listed in Table 2. Each solution took 10000 iterations to converge, but the $k-\varepsilon$ solutions required more CPU time than the algebraic model solutions. The two $k-\varepsilon$ model solutions took the same amount of CPU time to obtain the same number of iterations even though the Speziale calculations required a larger grid $(81 \times 81)$ than the Chien calculations ( $81 \times 51)$. For the implementations used in PARC, the Speziale model requires less CPU time per iteration per grid point than the Chien model.

Table 2.- Convergence histories for the no-shock flow.

\begin{tabular}{|l|c|c|}
\hline Case & Iterations & $\begin{array}{c}\text { Cray Y/MP } \\
\text { CPU time (s) }\end{array}$ \\
\hline Thomas & 10000 & 600 \\
Baldwin-Lomax & 10000 & 600 \\
MMLT & 10000 & 600 \\
Chien k- $\varepsilon$ & 10000 & 1700 \\
Speziale k- $\varepsilon$ & 10000 & 1700 \\
\hline
\end{tabular}

\section{Weak-Shock Case}

The next flow examined was that producing a weak shock in the diffuser. This flow was initialized by setting the outflow static pressure to a very small value $(R=0.12)$ to allow supersonic flow to exist from the throat to the exit plane. The back pressure was then set to its correct level for this flow $(R=0.82)$ to allow a shock to form slightly downstream of the throat (see Mach number contours for the Chien solution in Fig. 6). As with the no-shock case, these weak-shock calculations were continued until the solutions did not change. The experimental results described in Refs. 14 and 15 indicated some very small self-induced oscillations about the mean flow. All the PARC calculations reached non-oscillatory solutions, as expected since PARC was run in steady-state mode.

Pressure distributions along the top and bottom walls of the diffuser from the PARC calculations are compared with the mean flow experimental pressures in Fig. 7. All calculated pressure distributions agree relatively well with the experimental data except for the Speziale solution, which predicts the pressure to rise on the top and bottom walls much earlier than the other solutions or experimental data.

Velocity profiles obtained from the PARC calculations are compared to laser Doppler velocimeter data (documented in Ref. 14 for the weak-shock case discussed here and the strong-shock case discussed in the next section) in Fig. 8. At $x / H_{\mathrm{T}}=1.729$, the Baldwin-Lomax solution indicates that the flow is just passing through the weak shock while the other solutions and data indicate that the shock occurred upstream. As a result, the Baldwin-Lomax 
velocities are nearly sonic in the core of the flow at this location (Fig. 8a) while the core flow velocities of the other solutions are subsonic.

The maximum Mach numbers in the diffuser for each solution are listed in Table 3. The experimental value listed is the Mach number just outside the upper-wall boundary layer. The positions of the shock in the core of the flow obtained from the PARC calculations and the experimental data are also given in Table 3. For the PARC calculations, the positions of the shocks were determined to be the locations where the maximum drop in Mach number from any streamwise point to the next downstream point occurred. These shock positions correspond to the pressure distributions of Fig. 7 and the velocity profiles of Fig. 8. The Speziale solution, for example, predicted both the shock and the associated rise in static pressure to occur upstream of the other PARC solutions and experimental data while the Baldwin-Lomax solution predicted both to occur further downstream of the other solutions and experimental data.

Table 3.- Calculated flow properties for the weak-shock flow.

\begin{tabular}{|l|c|c|}
\hline Case & $\begin{array}{c}\text { Shock position } \\
\text { (throat heights, } \mathrm{H}_{\text {一 }} \text { ) }\end{array}$ & $\begin{array}{l}\text { Maximum Mach } \\
\text { number in duct }\end{array}$ \\
\hline Thomas & 1.615 & 1.285 \\
Baldwin-Lomax & 1.690 & 1.298 \\
MMLT & 1.537 & 1.255 \\
Chien k- $\varepsilon$ & 1.283 & 1.216 \\
Speziale k- $\varepsilon$ & .884 & 1.153 \\
Salmon Data & 1.47 & 1.235 (upper wall) \\
\hline
\end{tabular}

Convergence information from the PARC calculations is presented in Table 4. The Baldwin-Lomax solution took the most iterations to achieve steady state. The $\mathrm{k}-\varepsilon$ solutions required the fewest iterations, but the most $\mathrm{CPU}$ time.

Table 4.- Convergence histories for the weak-shock flow.

\begin{tabular}{|l|c|c|}
\hline Case & Iterations & $\begin{array}{c}\text { Cray Y/MP } \\
\text { CPU time (s) }\end{array}$ \\
\hline Thomas & 25000 & 1400 \\
Baldwin-Lomax & 30000 & 1800 \\
MMLT & 25000 & 1500 \\
Chien k- $\varepsilon$ & 16000 & 2800 \\
Speziale k- $\varepsilon$ & 16000 & 2800 \\
\hline
\end{tabular}

Strong-Shock Case

The last diffuser flow examined with PARC was the flow forming a strong shock $(R=0.72)$. These calculations were also begun with a very low back pressure $(R=0.12)$ to set supersonic flow in the diffuser from the throat to the exit plane. The back pressure was then increased to the correct outflow static pressure. After each calculation was run for 30000 iterations, only the Chien and Speziale calculations reached steady solutions. The three calculations using algebraic turbulence models demonstrated oscillations in the flow that did not decay with more iterations, although PARC was still being run in steady-state mode.
When it was determined that the algebraic turbulence model solutions were not going to reach steady state, the calculations were started again using the same initial conditions with supersonic flow from the throat to the exit plane. All 3 calculations obtained with the algebraic turbulence models were run for 8000 iterations, which was sufficient to allow the strong shock to form in the general region of the diffuser where the shock was oscillating during the previous iterations. At this point, all three calculations were run for 8 sets of 4000 iterations each (32000 iterations for each calculation after the initial 8000 iterations) to obtain 8 intermediate solutions for each calculation that could be averaged to provide mean flow properties. References 14 and 18 indicate that the magnitudes of the self-induced oscillations for this strong-shock case are considerably higher than those for the weak-shock case. This natural unsteadiness in the flow is probably a major reason for the inability of PARC (using the algebraic turbulence models) to produce steady solutions.

Figure 9 compares the PARC results to the experimental mean flow pressure distributions. Pressure distributions for each algebraic turbulence model were obtained by averaging the eight intermediate solutions stored for each model. The $\mathrm{k}-\varepsilon$ solutions (the only solutions not averaged because they were not oscillatory) match the experimental pressure profiles best. The experimental data indicate that the flow separates from the top wall because of the strong shock and reattaches at about six throat heights downstream of the throat. All the PARC solutions predict the flow separation from the top wall due to the shock, but only the $k-\varepsilon$ solutions predict reattachment within the computational domain. This may be observed in the velocity profiles shown in Fig. 10. The Chien solution predicts a reattachment location at 5.4 throat heights downstream of the throat and the Speziale solution predicts a reattachment at 5.9 throat heights. At $x / \mathrm{H}_{\mathrm{T}}=6.340$ (Fig. 10c) and $\mathrm{x} / \mathrm{H}_{\mathrm{T}}=$ 7.493 (Fig. 10d) the algebraic solutions all have large flow reversal regions near the top wall. These much larger flow separations also contributed to the inability of the algebraic solutions to converge.

Figure 11 shows gray-scale Mach number contours for the Chien solution and Table 5 gives the maximum Mach numbers in the duct and the shock positions for the PARC solutions and the experimental data. For the algebraic turbulence model solutions, the shock positions are averaged. The standard deviations of the pressure distributions for the algebraic model solutions are shown in Fig. 12. Overall, the Baldwin-Lomax solution shows the largest variation, particularly near the shock location, while the Thomas solution has the smallest variation. The convergence histories for the solutions are given in Table 6. 
Table 5.- Calculated flow properties for the strong-shock flow.

\begin{tabular}{|l|c|c|}
\hline Case & $\begin{array}{l}\text { Shock position } \\
\text { (throat heights, } \mathrm{H}_{\tau} \text { ) }\end{array}$ & $\begin{array}{l}\text { Maximum Mach } \\
\text { number in duct }\end{array}$ \\
\hline Thomas & 2.413 & 1.422 \\
Baldwin-Lomax & 2.224 & 1.383 \\
MMLT & 2.350 & 1.405 \\
Chien k- $\varepsilon$ & 2.444 & 1.416 \\
Speziale k- $\varepsilon$ & 2.161 & 1.373 \\
Salmon Data & 2.39 & 1.353 (upper wall) \\
\hline
\end{tabular}

Table 6.- Convergence histories for the strong-shock flow.

\begin{tabular}{|l|c|c|}
\hline Case & Iterations & $\begin{array}{c}\text { Cray Y/MP } \\
\text { CPU time (s) }\end{array}$ \\
\hline Thomas & 40000 & 2400 \\
Baldwin-Lomax & 40000 & 2400 \\
MMLT & 40000 & 2400 \\
Chien k- $\varepsilon$ & 30000 & 5000 \\
Speziale k- $\varepsilon$ & 30000 & 5000 \\
\hline
\end{tabular}

\section{Conclusions}

An evaluation of five turbulence models available in the PARC code, an internal flow Navier-Stokes solver used extensively by the propulsion community, has been conducted for flows through a two-dimensional transonic diffuser. These models are the Thomas, Baldwin-Lomax, and Modified Mixing Length Thomas (MMLT) algebraic turbulence models and the Chien and Speziale low Reynolds number k- $\varepsilon$ (two-equation) models. Three diffuser flows, having different flow conditions characterized by the ratio of the outflow static pressure to the inflow total pressure, were calculated. These flows, which are representative of many inlet cases to which PARC has been applied, were referred to as the no-shock, weak-shock, and strong-shock cases.

Overall, the Chien $k-\varepsilon$ model was the most accurate of the five turbulence models when all three flows are considered. However, the MMLT model provided results as accurate as those of the Chien model for the no-shock case and the weak-shock case at a significantly lower computational cost (measured in CPU seconds required to provide converged solutions). For the strong-shock case, only the Chien and Speziale k- $\varepsilon$ models produced steady-state solutions. None of the PARC calculations using the algebraic turbulence models reached steady state, but 8 intermediate solutions were obtained at 4000 iteration increments for each model and averaged to provide mean flow properties. The experimental data indicates that the strong-shock flow demonstrates large scale unsteadiness, unlike the no-shock and weak-shock flows. This probably contributes to the inability of the algebraic model calculations to reach steady state. The comparison of the averaged algebraic model solutions and steady $k-\varepsilon$ solutions to the experimental mean flow properties indicates that the two k- $\varepsilon$ solutions matched the experimental data best.
As improvements in turbulence models continue to be made; the availability of several turbulence models (e.g. both algebraic and two-equation models) in a multipurpose Navier-Stokes code like PARC allows selection of the turbulence model appropriate for the flow to be analyzed. For flows where an algebraic model may be expected to provide results as accurate as a more sophisticated turbulence model (like $\mathrm{k}-\varepsilon$ ), using the algebraic turbulence model would save computational resources and require less time to obtain solutions. For more difficult flows where an algebraic model would not produce flow predictions as accurate as a more complex model, using the more complex model would be justified.

\section{$\underline{\text { References }}$}

1. Cooper, G.K. and Sirbaugh, J.R., "The PARC Distinction: A Practical Flow Simulator," AIAA Paper 90-2002, July 1990.

2. Cooper, G.K. and Sirbaugh, J.R., "PARC Code: Theory and Usage," Arnold Engineering Development Center Report AEDC-TR-89-15, Arnold AFS, TN, Dec. 1989.

3. Pulliam, T.H., "Euler and Thin Layer Navier-Stokes Codes: ARC2D, ARC3D." Notes for Computational Fluid Dynamics User's Workshop, The University of Tennessee Space Institute, Tullahoma, Tennessee, (UTSI Publication E02-4005-023-84), 1984, pp. 15.115.85 .

4. Pulliam, T.H. and Steger, J.L., "Implicit Finite Difference Simulations of Three Dimensional Compressible Flow," AIAA Journal, Vol. 18., No. 2, 1980, pp. 159-167.

5. Beam, R.M., and Warming, R.F., "An Implicit Finite Difference Algorithm for Hyperbolic Systems in Conservation-Law Form-Application to Eulerian Gasdynamic Equations," Journal of Computational Physics, Vol. 22, No. 1, 1976, pp. 87-110.

6. Jameson, A., Schmidt, W., and Turkel, E.,"Numerical Solutions of the Euler Equations by Finite Volume Method for Solving the Euler and Navier-Stokes Equations for High Speed Flows," AIAA Paper 811259, June 1981.

7. Thomas, P.D., "Numerical Method for Predicting Flow Characteristics and Performance of Nonaxisymmetric Nozzles, Theory," NASA CR-3147, 1979.

8. Baldwin, B. and Lomax, H., "Thin Layer Approximation and Algebraic Model for Separated Turbulent Flows," AIAA Paper 78-257, Jan. 1978. 
9. Potapczuk, M.G., "Navier-Stokes Analysis of Airfoils with Leading Edge Ice Accretions," Ph.D. Thesis, The University of Akron, Akron, OH, May 1989.

10. Georgiadis, N.J., Drummond, J.E., and Leonard, B.P., "Development of an Algebraic Turbulence Model for Analysis of Propulsion Flows," AIAA Paper 92-3861, July 1992.

11. Chien, K.-Y., "Predictions of Channel and Boundary Layer Flows with a Low-Reynolds-Number Turbulence Model," AIAA Journal, Vol. 20, No. 1, 1982, pp. 33-38.

12. Nichols, R.H., "A Two-Equation Model for Compressible Flows," AIAA Paper 90-0494, Jan. 1990.

13. Speziale, C.G., Ridha, A., and Anderson, E.C., "A Critical Evaluation of Two-Equation Turbulence Models for Near Wall Turbulence," NASA CR182068, 1990.

14. Salmon, J.T., Bogar, T.J., and Sajben, M., "Laser Doppler Velocimeter Measurements in Unsteady, Separated, Transonic Diffuser Flows," AIAA Journal, Vol. 21, No. 12, 1983, pp. 1690-1697.

15. Bogar, T.J., Sajben, M., and Kroutil, J.C., "Characteristic Frequencies of Transonic Diffuser Flow Oscillations," AIAA Journal, Vol. 21, No. 9, 1983, pp. 1232-1240.

16. Sajben, M. and Kroutil, J.C., "Effects of Initial Boundary-Layer Thickness on Transonic Diffuser Flows," AIAA Journal, Vol. 21, No. 12, 1983, pp.1690-1697.
17. Hsieh, T., Bogar, T.J., and Coakley, T. J., "Numerical Simulation and Comparison with Experiment for Self-Excited Oscillations in a Diffuser Flow," AIAA Journal, Vol. 25, No. 7, 1987, pp. 936-943.

18. Hsieh, T., Wardlaw, A. B. Jr., Collins, P., and Coakley, T., "Numerical Investigation of Unsteady Inlet Flowfields," AIAA Journal, Vol. 25, No. 1, 1987, pp. 75-81.

19. Bui, T.T., "Implementation/Validation of a Low Reynolds Number Two-Equation Turbulence Model in the Proteus Navier-Stokes Code - Two-Dimensional /Axisymmetric," NASA TM-105619, Apr. 1992.

20. Towne, C.E., Schwab, J.R., Benson, T.J., and Suresh, A., "PROTEUS Two- Dimensional Navier-Stokes Computer Code - Version 1.0, Vol. 1: Analysis Description," NASA TM-102551, 1990.

21. Towne, C.E., Schwab, J.R., Benson, T.J., and Suresh, A., "PROTEUS Two- Dimensional Navier-Stokes Computer Code - Version 1.0, Vol. 2: User's Guide," NASA TM-102552, 1990.

22. Towne, C.E., Schwab, J.R., Benson, T.J., and Suresh, A., "PROTEUS Two- Dimensional Navier-Stokes Computer Code - Version 1.0, Vol. 3: Programmer's Reference,"NASA TM-102553, 1990.

23. Avva, R.K., Smith, C.E., and Singhal, A.K., "Comparative Study of High and Low Reynolds Number Versions of k- $\varepsilon$ Models," AIAA Paper 90-0246, Jan. 1990. 


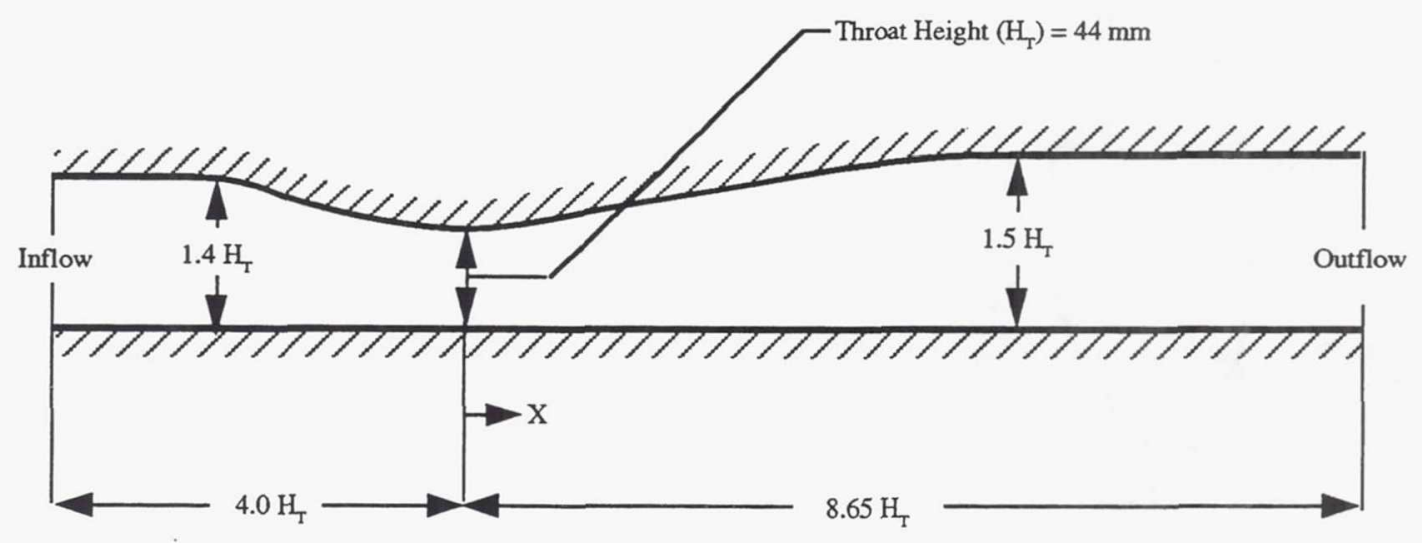

Figure 1 - Diffuser geometry.

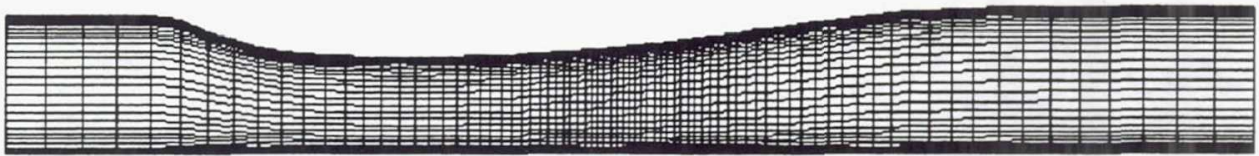

a. $81 \times 51$ grid.

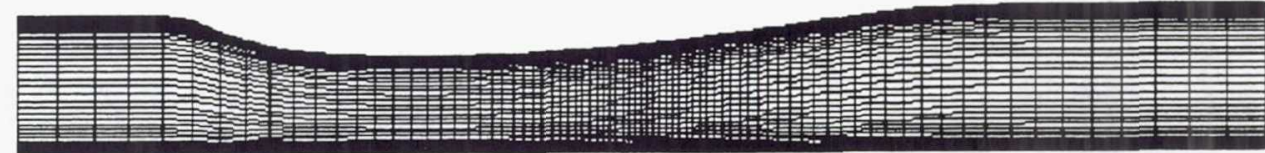

b. 81 x 81 grid.

Figure 2 - Computational grids for diffuser flow cases.

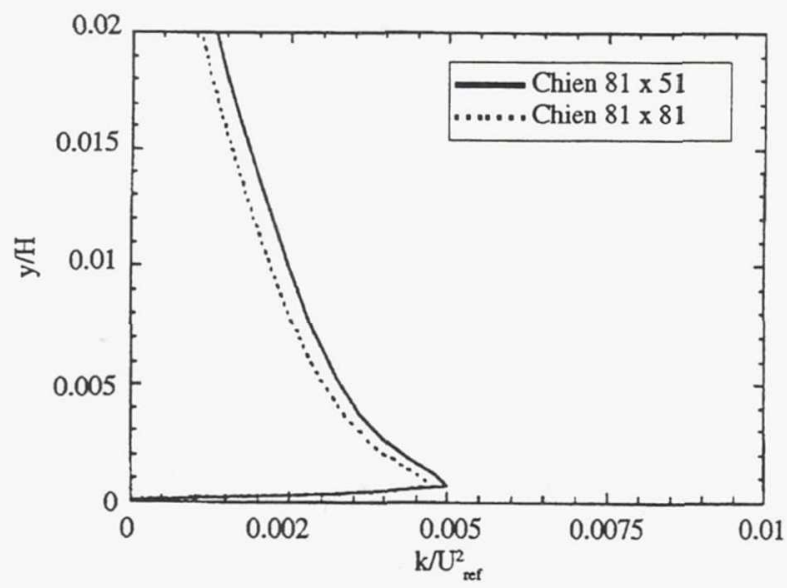

a. Chien k- $\varepsilon$ model.

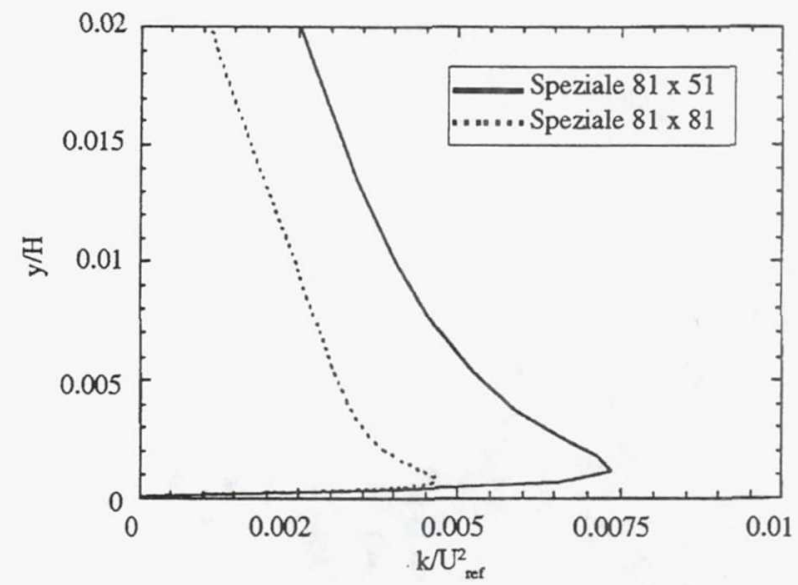

b. Speziale k- $\varepsilon$ model.

Figure 3 - Turbulent kinetic energy profiles at the throat (no-shock case). 


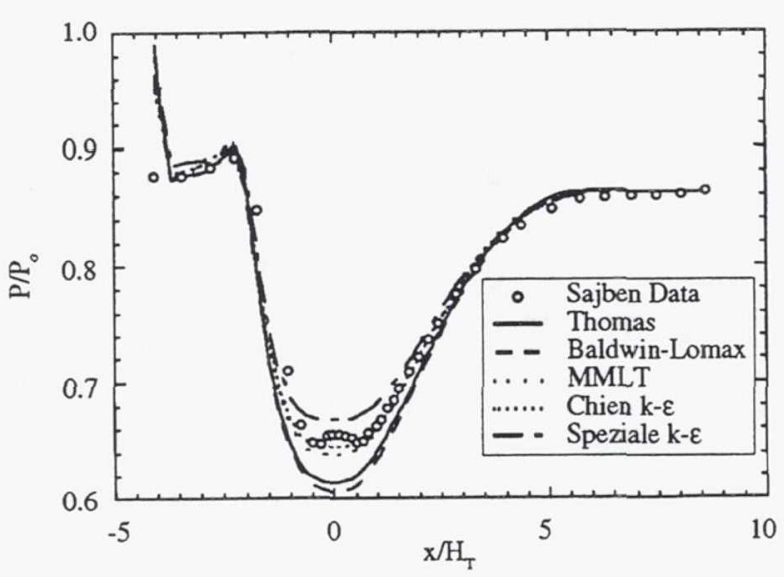

a. Top wall.

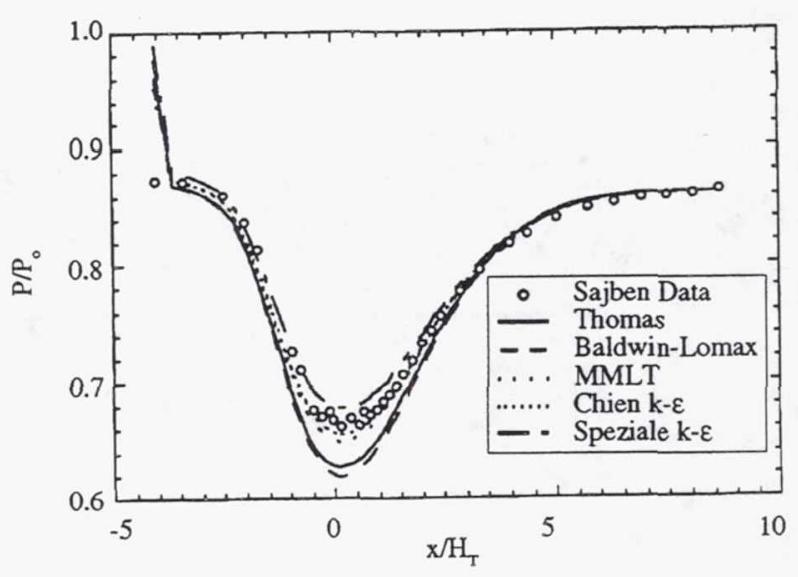

b. Bottom wall.

Figure 4 - Pressure distributions for the no-shock case.
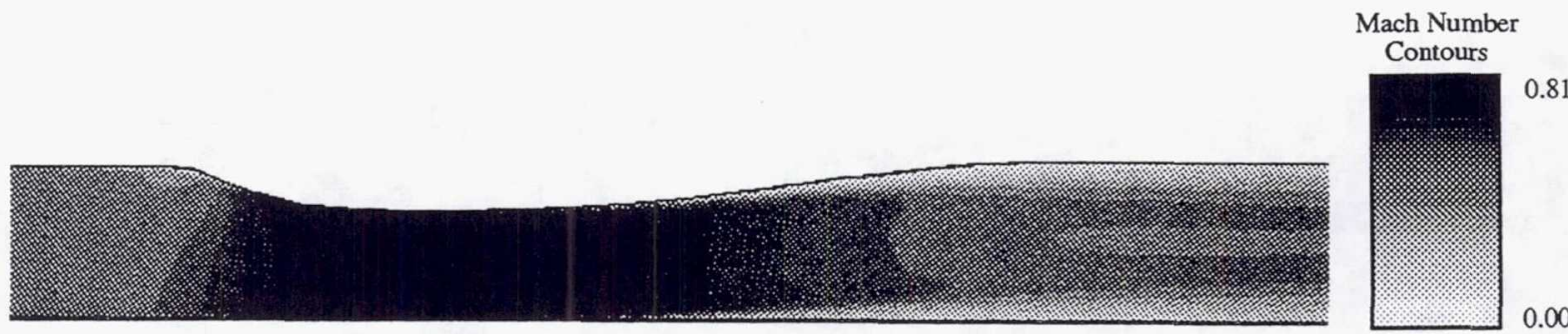

Figure 5 - Mach number contours for the no-shock case (Chien k- $\varepsilon$ solution).

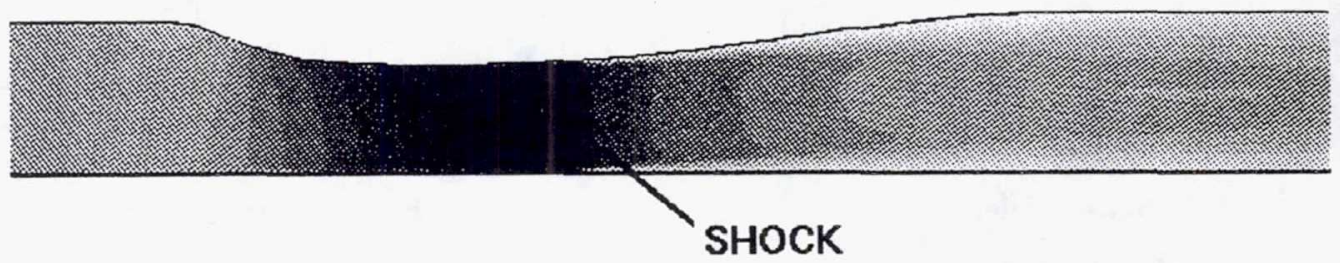

Figure 6 - Mach number contours for the weak-shock case (Chien k- $\varepsilon$ solution). 


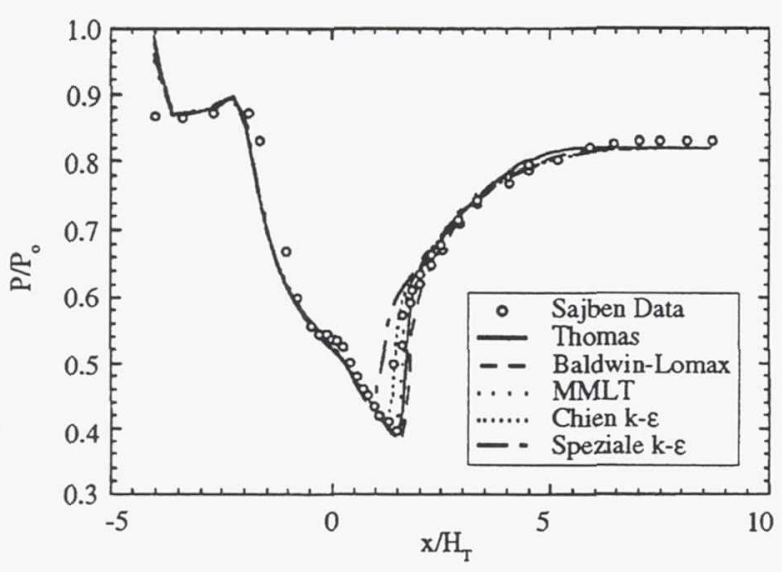

a. Top wall.

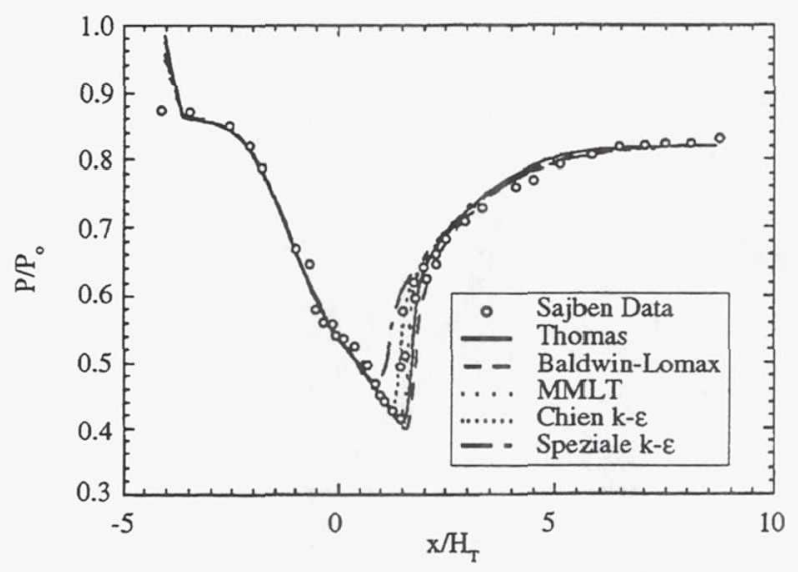

b. Bottom wall.

Figure 7 - Pressure distributions for the weak-shock case.

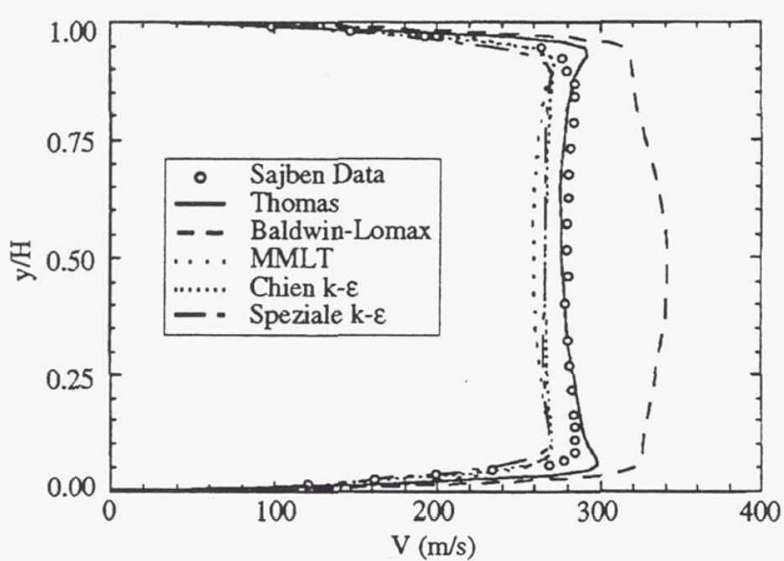

a. $\mathbf{x} / \mathbf{H}=\mathbf{1 . 7 2 9}$

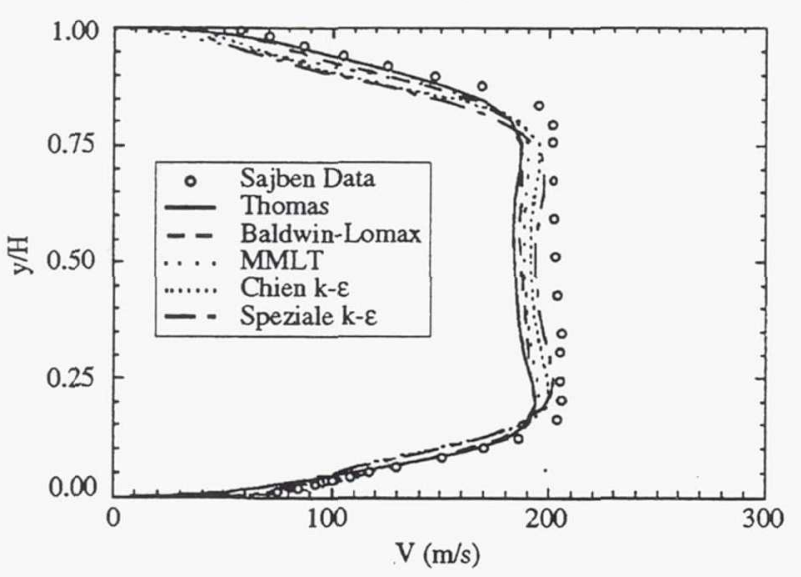

c. $\mathrm{x} / \mathrm{H}=\mathbf{4 . 6 1 1}$

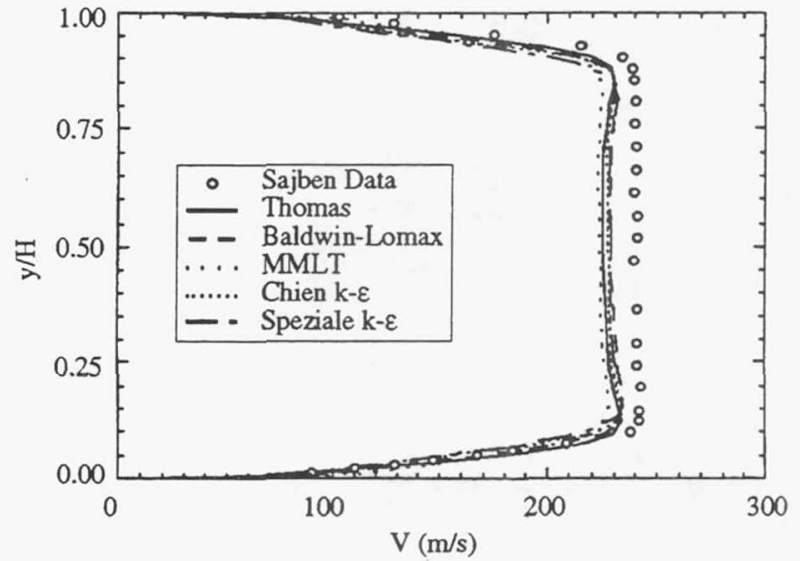

b. $\mathbf{x} / \mathbf{H}=\mathbf{2 . 8 8 2}$

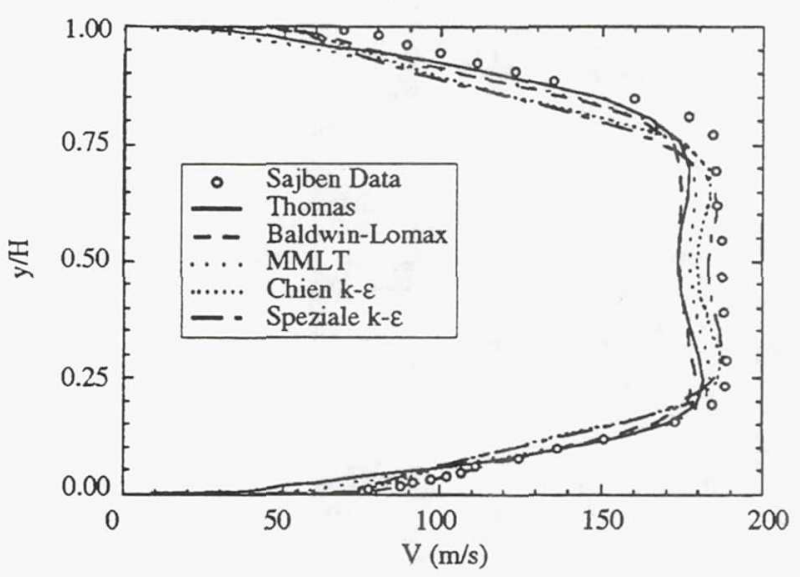

d. $\mathrm{x} / \mathrm{H}=6.340$

Figure 8 - Velocity profiles for the weak-shock case. 


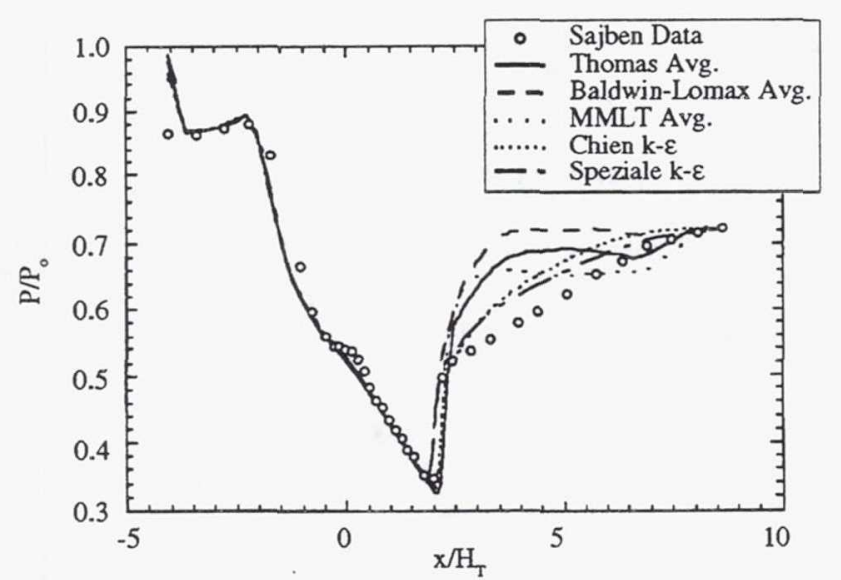

a. Top wall.

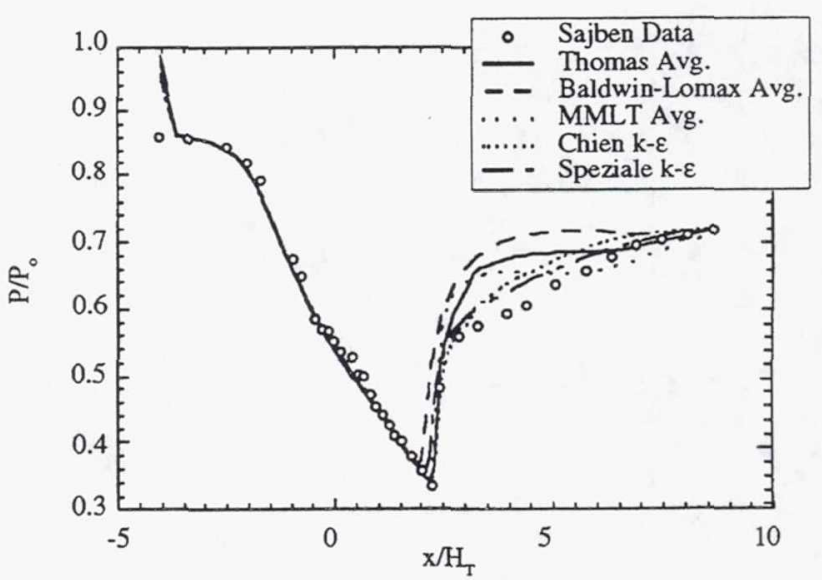

b. Bottom wall.

Figure 9- Pressure distributions for the strong-shock case.

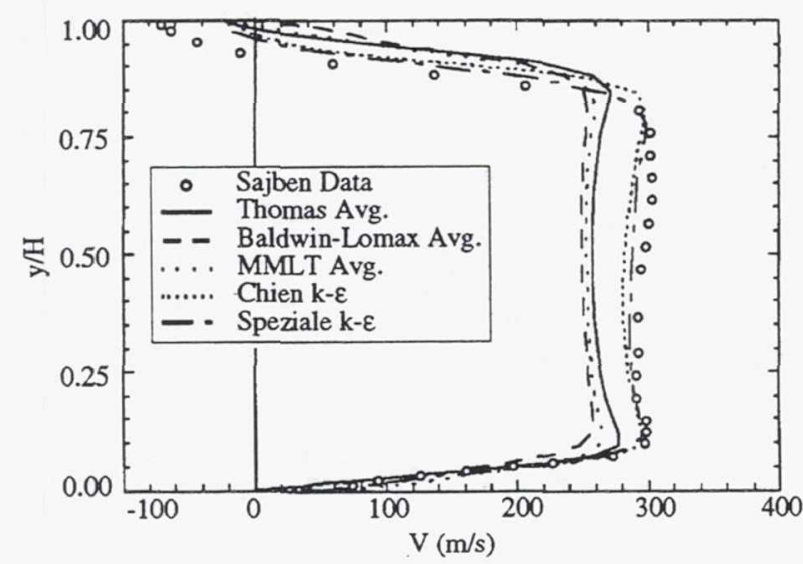

a. $\mathrm{x} / \mathrm{H}=\mathbf{2 . 8 8 2}$

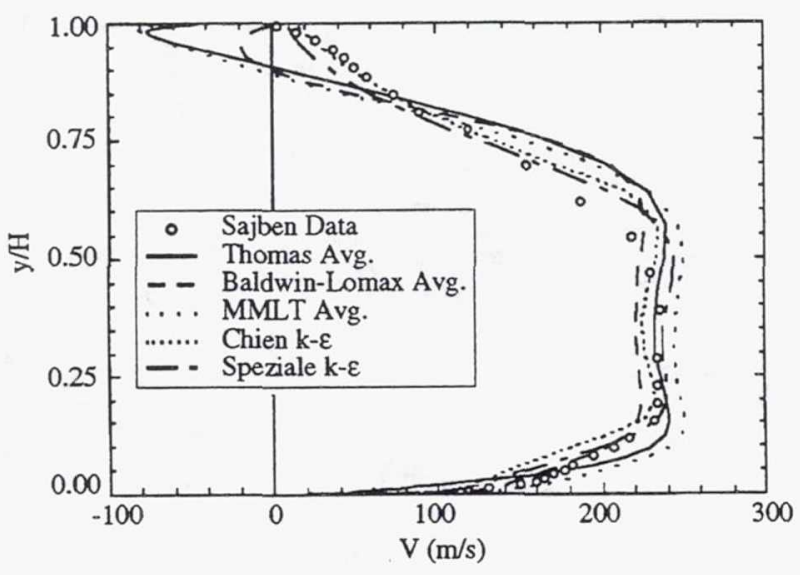

c. $\mathrm{x} / \mathrm{H}=\mathbf{6 . 3 4 0}$

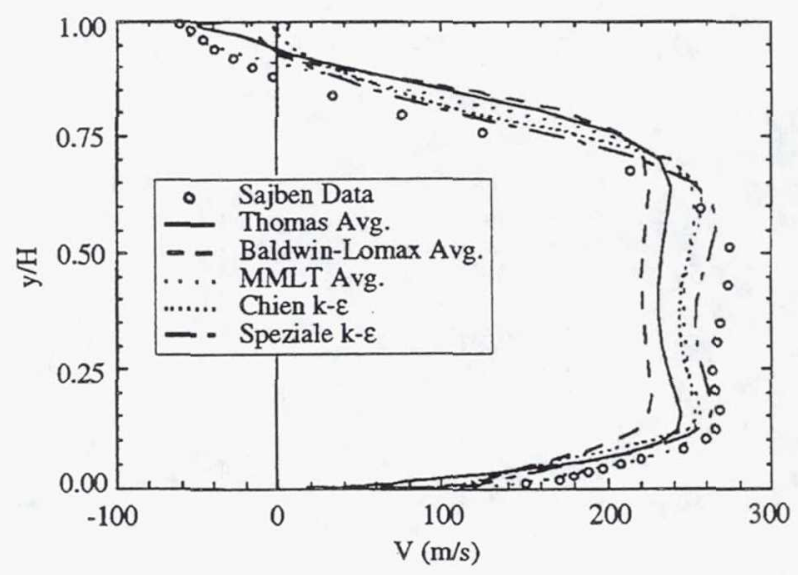

b. $\mathrm{x} / \mathrm{H}=\mathbf{4 . 6 1 1}$

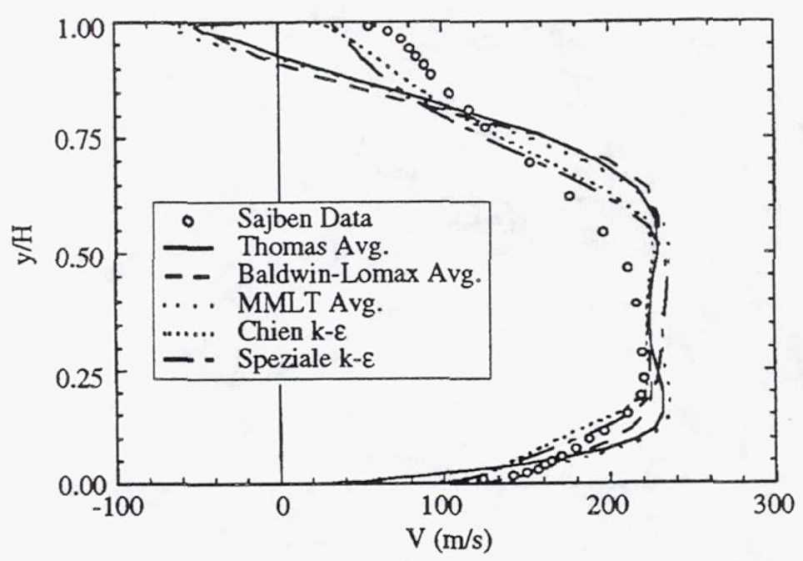

d. $\mathrm{x} / \mathrm{H}=\mathbf{7 . 4 9 3}$

Figure 10 - Velocity profiles for the strong-shock case. 


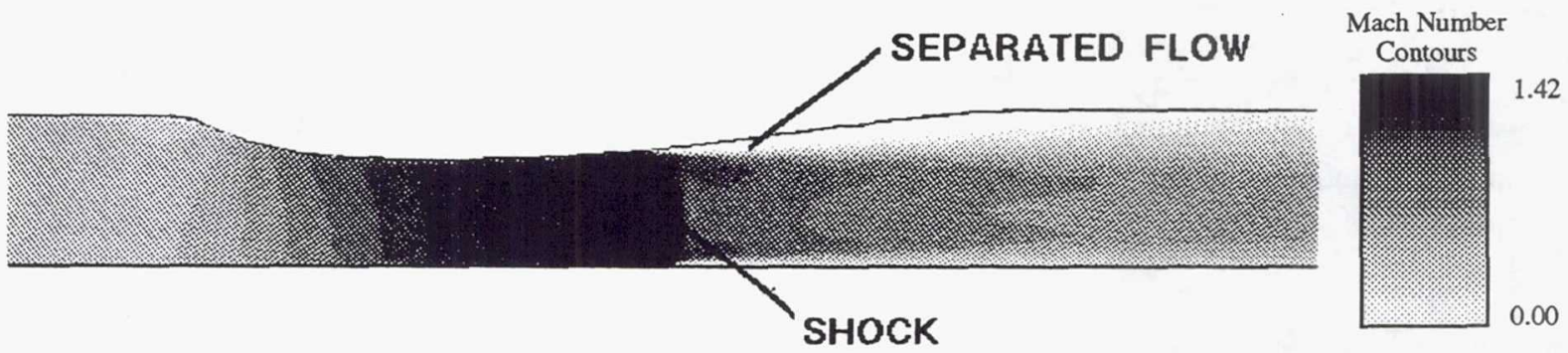

Figure 11 - Mach number contours for the strong-shock case (Chien k- $\varepsilon$ solution).

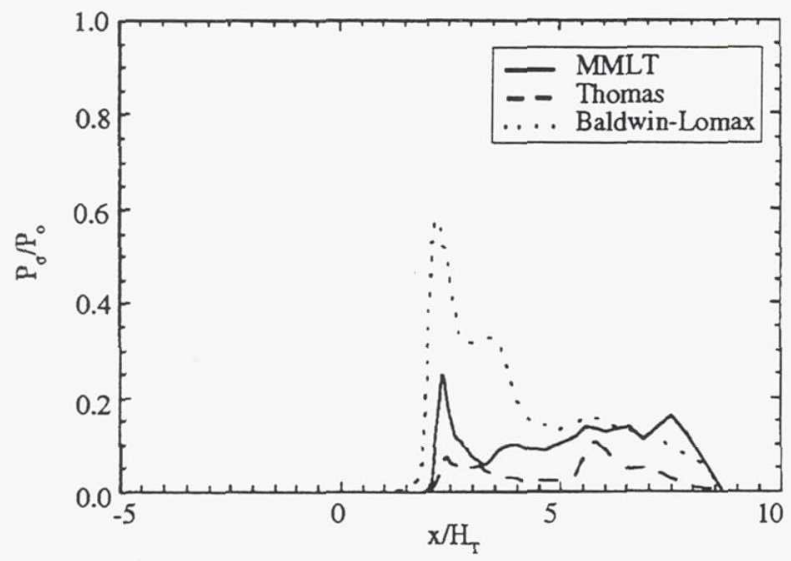

a. Top wall.

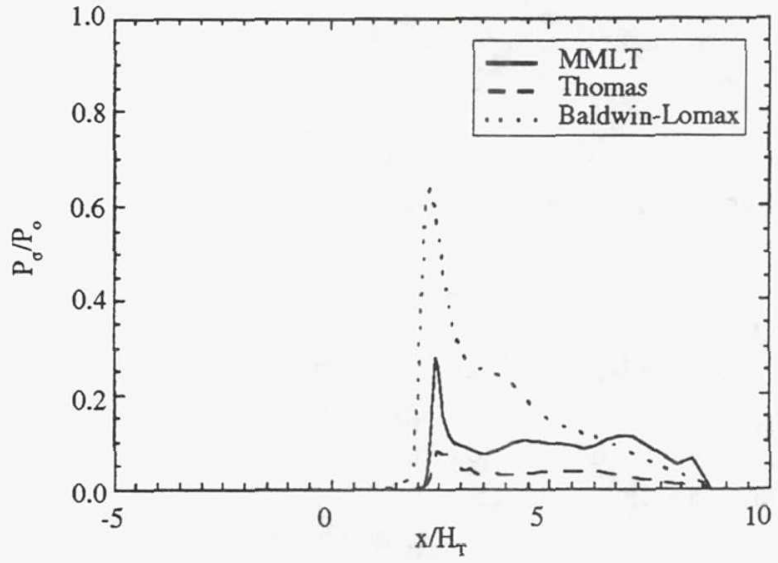

b. Bottom wall.

Figure 12-Standard deviations of pressure for the strong-shock case. 
Public reporting burden for this collection of information is estimated to average 1 hour per response, including the time for reviewing instructions, searching existing data sources, gathering and maintaining the data needed, and completing and reviewing the collection of information. Send comments regarding this burden estimate or any other aspect of this collection of information, including suggestions for reducing this burden, to Washington Headquarters Services, Directorate for Information Operations and Reports, 1215 Jefferson Davis Highway, Suite 1204, Arlington, VA 22202-4302, and to the Office of Management and Budget, Paperwork Reduction Project (0704-0188), Washington, DC 20503.

\begin{tabular}{l|l|l|} 
1. AGENCY USE ONLY (Leave blank) & 2. REPORT DATE & 3. REPORT TYPE AND DATES COVERED
\end{tabular}

\begin{tabular}{|l|l|l} 
January 1994 & Technical Memorandum \\
\hline
\end{tabular}

\section{TITLE AND SUBTITLE}

Evaluation of Turbulence Models in the PARC Code for Transonic Diffuser Flows

\section{FUNDING NUMBERS}

6. AUTHOR(S)

WU-537-02-23

N.J. Georgiadis, J.E. Drummond and B.P. Leonard

7. PERFORMING ORGANIZATION NAME(S) AND ADDRESS(ES)

National Aeronautics and Space Administration

Lewis Research Center

Cleveland, Ohio 44135-3191

8. PERFORMING ORGANIZATION REPORT NUMBER

E-8216

9. SPONSORING/MONITORING AGENCY NAME(S) AND ADDRESS(ES)

10. SPONSORING/MONITORING AGENCY REPORT NUMBER

National Aeronautics and Space Administration

Washington, D.C. 20546-0001

NASA TM-106391

AIAA-94-0582

11. SUPPLEMENTARY NOTES

Prepared for the 32nd Aerospace Sciences Meeting and Exhibit sponsored by the American Institute of Aeronautics and Astronautics, Reno, Nevada, January 10-13, 1994. N.J. Georgiadis, NASA Lewis Research Center and J.E. Drummond and B.P. Leonard, The University of Akron, Akron, Ohio 44325. Responsible person, N.J. Georgiadis, (216) 433-3958.

12a. DISTRIBUTION/AVAILABILITY STATEMENT

12b. DISTRIBUTION CODE

Unclassified - Unlimited

Subject Category 02

13. ABSTRACT (Maximum 200 words)

Flows through a transonic diffuser were investigated with the PARC code using five turbulence models to determine the effects of turbulence model selection on flow prediction. Three of the turbulence models were algebraic models: Thomas (the standard algebraic turbulence model in PARC), Baldwin-Lomax, and Modified Mixing Length-Thomas (MMLT). The other two models were the low Reynolds number k- $\varepsilon$ models of Chien and Speziale. Three diffuser flows, referred to as the no-shock, weak-shock, and strong-shock cases, were calculated with each model to conduct the evaluation. Pressure distributions, velocity profiles, locations of shocks, and maximum Mach numbers in the duct were the flow quantities compared. Overall, the Chien $\mathrm{k}-\varepsilon$ model was the most accurate of the five models when considering results obtained for all three cases. However, the MMLT model provided solutions as accurate as the Chien model for the no-shock and the weak-shock cases, at a substantially lower computational cost (measured in CPU time required to obtain converged solutions). The strong shock flow, which included a region of shock-induced flow separation, was only predicted well by the two k- $\varepsilon$ models.

\section{SUBJECT TERMS}

Diffuser; Inlet; Navier-Stokes, PARC code; Shock; Transonic; Turbulence model

\begin{tabular}{c} 
15. NUMBER OF PAGES \\
12 \\
\hline $\begin{array}{c}\text { 16. PRICE CODE } \\
\text { AO3 }\end{array}$
\end{tabular}

17. SECURITY CLASSIFICATION OF REPORT

Unclassified
18. SECURITY CLASSIFICATION OF THIS PAGE

Unclassified
19. SECURITY CLASSIFICATION OF ABSTRACT

Unclassified 